\title{
Die interfererende kontoere van Nijhoff en Cloete se poëtika
}

\author{
Adéle Nel \& Tom Gouws \\ Departement Afrikaans \\ Universiteit van die Noordweste \\ MMABATHO
}

\begin{abstract}
The interferential contours of Nijhoff and Cloete's poetics
\end{abstract}

In the poetry of T.T. Cloete the recycling or idiolectical transformation of texts from the Dutch literary tradition can clearly be demonstrated. The aim of this article is to explore the manner in which Cloete's poetics manifests itself verse-externally and verseinternally, and to indicate the interactional views of the poetry of Cloete and the Dutch poet Nijhoff. In the article it is demonstrated that those views which Cloete shares with Nijhoff manifest themselves in his poetry. The contours of these theories are views of the origins of poetry, a world view and a theory of objectivity. The nub of the shared views centres in the concept of the wilfulness of language which is linked synchronically to the so-called autonomistic poetics of the Utrecht model.

\section{Inleiding}

Aan die term poëtika is in die loop van die eeue verskillende betekenisse gegee. In beginsel het poëtika betrekking op alle vorme en tegnieke van literatuur en op alle genres. Afgespits op die poësie het die poëtika te make met die kompleks van literatuurkonsepsies oor die ontstaan van die gedig, die wesensaard van die poësie, die middele of literêre tegnieke wat die digter aanwend in die totstandkoming van die gedig en die funksie van die poësie. Die poëtika van 'n digter kan op twee wyses gelees word, naamlik versintern en versekstern - 'n leeswyse wat weer in twee onderafdelings verdeel kan word: implisiet en eksplisiet. Die poëtika van 'n digter kan beskryf word deur middel van 'n ondersoek na al hierdie kategorieë. (Vergelyk Nel, 1992 in dié verband.)

Die poësie van die digter T.T. Cloete getuig ook van 'n eie versinterne poëtika wat ooreenkom met sy verseksterne uitsprake ten opsigte van die poëtika. 
Terselfdertyd toon hierdie opvattings verwantskappe met verseksterne, sowel as versinterne uitsprake van die Nederlandse digter Martinus Nijhoff. Cloete (1970) se belangrikste uitsprake ten opsigte van die poëtika kom voor in die artikel "J.H. Leopold oor die dromende denke" - 'n artikel waarvan hy later (1984b:1) sê: "Dit was alles eintlik 'n bevestiging van my eie skryfervaring". Aanvullend hierby is die kongresreferaat (Cloete, 1984b) getitel "Die dromende denke van die digter". Fragmentariese uitsprake ten opsigte van sy opvattings oor die digkuns kom voor in onderhoude met koerante en tydskrifte. Nijhoff (1982b) sit sy verseksterne poëtika in talle prosastukke uiteen, waarvan die belangrikste drie die volgende is: sy opstel "Herman van den Bergh" (Nijhoff, 1982b:338-342), "De pen op papier" (Nijhoff, 1982b:1063-1080), en "Over eigen werk" (Nijhoff, 1970:7-32).

Die belangrikste spilpunte waaromheen die poëtikale opvattings van albei digters geweef is, is opvattings (ooreenkomstig sowel as genuanseerd verskillend) ten opsigte van die teks (wat insluit beskouings oor die ontstaanswyse van die poësie), bepaalde werklikheidsienings en die sogenaamde objektiveringsteorie, dit wil sê 'n bepaalde konsepsie oor die rol van die outeur. Ooreenstemmende poëtikale konsepsies oor die ontstaanswyse van die poësie sluit die volgende aspekte in: die opvatting dat invalle van buite aan die digter gegee word, die opvatting oor die selfaangedrewenheid van die gedig, inspirasie én tegniek as vereistes vir die voltooiing van die gedig, die drieledigheidskonsep as belangrike vormteorie en die siening van die gedig as outonome artefak.

Die doel van hierdie artikel is om die versinteme poëtika van T.T. Cloete na te gaan soos wat dit implisiet en/of eksplisiet uit 'n gekose eksemplariese gedig blyk. Die gedig "loopskrif in 'n vakansiehotel" uit Idiolek (Cloete, 1986) is gekies vanwee 'n direkte of indirekte verwysing na, of verwantskap met 'n Nijhoff-teks (hetsy prosa of poësie). Die doel is dus ook om die verwantskap tussen die digkuns van Cloete en Nijhoff na te speur; 'n verwantskap wat manifesteer ten opsigte van die poëtika, sowel as op konseptuele en taalmanifestasievlak.

\section{Die verwantskap tussen Cloete en Nijhoff}

\section{loopskrif in 'n vakansiehotel}

ek sit en skryf by die lig beheers hier

in my vertrek en hoor die ritsel en kras

van my pen en van die papier

en tussendeur'n geswem en geplas 
en sien deur my venster ' $n$ ster uitbrand

jongmense in die aand in die water gier

en gil en die skerp lag verras

van 'n jongmeisiestem van plesier

'n orgasme onbeheerbaar op die terras

my pen staan orent luisterend in my hand

wanneer albei ontploffings bedaar

het kry die hand wat koud

geword het weer loop en klier en kwasar

soek daarin 'n nuwe behoud

en gaan aan en aan

waar dit daar aan die loop gaan

In die beskoulike artikel oor die dromende denke van die digter maak Cloete (1970:193) die belangrike uitspraak dat die gedig oor die gedig die natuurlike uitkoms van die dromende denke is; die gedig dus wat op beskoulike wyse geïnteresseerd is in sy eie ontstaanswyse en denkpatroon. Die gedig "loopskrif in 'n vakansiehotel" (Idiolek), met sy eksplisiete poëtikale nosies, is 'n gedig waarin dié opvatting gemanifesteer word. Die "loopskrif" van die titel impliseer reeds by die eerste oogopslag 'n poëtikale strekking en die gedig kommunikeer inderdaad 'n verslag oor die ontstaanswyse van die poësie - 'n siening wat aansluit by Nijhoff sowel as Cloete se verseksterne opvattings.

Versreël 3: "my pen ... die papier" lê 'n duidelike verband met Nijhoff se verseksterne poëtika, want dit is waarskynlik 'n direkte verwysing na Nijhoff se geskrif "De pen op papier".

Nijhoff se gedig, "Sonnet 1" van die siklus "Voor dag en dauw" (Nijhoff, 1970:193) dwing hom ook aan die leser op vanweè simultane beelde en ooreenkomstige woordgebruik.

\section{Sonnet 1}

De tekentafel voor het brede raam

bewaart van 't sterrenbeeld voorbijgevlogen

een spoor op het papier; passer, potloden

liggen gedrenkt door de verdwenen maan.

De booglamp, op ' $t$ fabrieksterrein nog aan,

slaapt lachend in, als op haar bed een dode, 
nu zij, voor ' $t$ werkmanstreintje uit stad ontboden

de klokjes langs de lijn heeft horen slaan.

De ingenieur, om 't heerlijke gesuis

van de machines, droomt, hij laat zijn huis

later, vlak tegen de fabriek aan bouwen.

De vogel is het struikgewas ontsneld.

In grote stilte gaat over het veld

het langzaam licht zich als een hand ontvouwen.

Om 'n vergelyking te vergemaklik, word in die tabel aangedui hoe Cloete by Nijhoff aansluit. Cloete sluit by Nijhoff aan ten op sigte van die volgende beelde en woordkeuse, hetsy ekplisiet of geimpliseerd:

\begin{tabular}{|c|c|}
\hline Nijhoff & Cloete \\
\hline $\begin{array}{l}\text { 1. "De tekentafel voor het brede } \\
\text { raam" }\end{array}$ & $\begin{aligned} 1 . \quad * & \text { "Ek sit en skryf" } \\
\text { * } & \text { "sien deur my venster" - by } \\
& \text { implikasie voor my venster }\end{aligned}$ \\
\hline 2. "'t sterrenbeeld voorbijgevlogen" & 2. "'n ster uitbrand" \\
\hline 3. "een spoor op het papier" & $\begin{array}{l}\text { 3. * “die papier" } \\
\text { * "loopskrif" (laat by implikasie } \\
\text { 'n spoor na } \\
\text { * "die hand ... gaan aan en aan } \\
\text { /waar dit daar aan die loop } \\
\text { gaan." }\end{array}$ \\
\hline $\begin{array}{l}\text { 4. "de klokjes langs de lijn horen } \\
\text { slaan" }\end{array}$ & $\begin{array}{l}\text { 4. * "gier/en gil die skerp lag" (by } \\
\text { implikasie hoor) } \\
\text { * "hoor die ritsel en kras" }\end{array}$ \\
\hline $\begin{array}{l}\text { 5. "het langzaam licht zich als een } \\
\text { hand ontvouen" }\end{array}$ & $\begin{array}{l}\text { 5. * "my hand" } \\
\text { "die hand" }\end{array}$ \\
\hline 6. "in grote stilte gaat" & $\begin{array}{l}\text { 6. "wanneer albei ontploffmgs } \\
\text { bedaar het (by implikasie } \\
\text { stilte). }\end{array}$ \\
\hline
\end{tabular}


Die beeld van die gestalte voor die venster of raam is in albei gedigte opvallend en verdien allereers aandag vanweë die besondere implikasies daarvan in die Cloete- én Nijhoff-oeuvre.

\subsection{Die beeld van die raam / venster}

As Bakker (1987:278) sê die raam is waarskynlik die mees voorkomende konvensionele beeld in Nijhoff se poësie, het hy heeltemal gelyk. Hy maak ook dié belangrike opmerking dat die beeld van die raam in een of ander variant in een derde van die gedigte in De wandelaar (1916) voorkom en deurgaans in die betekenis van afskeiding tussen die hoofpersoon en die wêreld. Reeds in die programmatiese openingsgedig van die bundel, met die gelyknamige titel, kom dié beeld voor:

Kloosterling uit den tijd der Carolingen,

Zit ik met ernstig Vlaamsch gelaat voor 't raam;

Zie menschen op een zonnig grasveld gaan,

En hoor matrozen langs de kaden zingen.

In Vormen (1924) is die gedigte waarin "raam" 'n prominente en simboliese funksie vertoon, talryk. 'n Enkele voorbeeld is die gedig "De jongen" waarvan die openingsreëls soos volg klink:

Hij zat in nachtgoed voor het raam en liet

Willoos het hoofd hangen op het kozijn -

Hij zag...

Die sintuiglike gegewe, benewens die beeld van die skrywer voor die raam/venster, het in Cloete se gedig eweneens prominensie:

Ek sit en skryf ...

... en hoor ...

... en sien ...

Die ooreenkoms wat die Cloete-gedig ten opsigte van die sintuiglike waarneming en die raambeeld met die Nijhoff-gedigte toon, is nie toevallig nie, want laasgenoemde gedigte het, soos "loopskrif in 'n vakansiehotel", eksplisiete poëtikale nosies. Albei die gesiteerde gedigte van Nijhoff kommunikeer naamlik opvattings in verband met die digterskap, wat op merkwaardige wyse ooreenstem met die verseksterne uitsprake. ('n Aspek wat in die loop van die bespreking nader toegelig sal word.)

Die perspektiwiese oriëntasiepunt in 'n literêre teks is 'n figuur; in hierdie geval die skrywersgestalte voor die venster/raam. In die eerste plek bied die 
venster 'n uitsig na buite - op reële vlak dus die plek van ingeskerpte sintuiglike waarneming en, soos Cloete (1984b:7) dit stel: "die kiem vir 'n gedig is 'n sintuiglike belewenis". Die visueel-sintuiglike belewing wat noodsaaklike digterlike toerusting is, geskied deur middel van die raam/venster. Die perspektief op die waargenome werklikheid is dikwels 'n register van belewenis: die omvattende lewe en kry juis deur middel van die venster groter reliëf.

In albei poëtikas is $k y k$ en skryf/dig onlosmaaklik aan mekaar verbonde; in die poësie kry die kreatiewe woord slegs deur middel van die kreatiewe oog vergestalting. Kyk gaan by die digter dikwels direk oor in $s k r y f$, net soos $k y k$ soms oorgaan in weet, ken of droom, dit wil sê beskoulik kyk. In 'n verseksterne uitspraak bevestig Cloete (1985) hierdie stelling as hy sê: "Die literatuur is ook niks anders nie as 'n glas waardeur jy kyk na die werklikheid." Die raam of venster as optiese instrument met sy refleksiemoontlikheid word op ideële vlak dikwels simbool van die beskoulike kyk, of dan van 'n inwendige blik na binne. Dit wat visueel-sintuiglik beleef word, word via die raam/venster getransponeer na die milieu van die abstrakte.

Die raam/venster as werklikheidsomlyning in die Cloete-gedig, sowel as in die gesiteerde Nijhoff-gedigte, dien in die tweede plek as 'n verbinding tussen twee wêrelde: 'n wêreld waarin die hooffiguur hom bevind, en die wêreld van die waargenome werklikheid. Die teenoorgestelde is natuurlik ook waar: die raam/venster kan juis dien as 'n skeidingsmiddel tussen die gewone afgeslote werklikheid waarin die persoon hom bevind en die gewone werklikheid wat deur die skeppende, artistieke oog waargeneem word. Op hierdie wyse word die gewone werklikheid los gemaak van reële, dinamiese verskyningsvorme en verduursaam in die artistieke vorm van die gedig. Dienooreenkomstig dien die raam/venster as objektiveringsmiddel. Die objektiveringsgedagte is 'n dwingende poëtikale gegewe in al drie die genoemde gedigte van Nijhoff. Die insetversreël van "De wandelaar" lui: "mijn eenzaam leven wandelt in de straten, / langs een landschap of tusschen kamerwanden", 'n bykans skisofrene formulering wat verskillende interpreteerders 'n verskeidenheid interpretasies laat maak het. Die dubbele persoonlikheid, wat hier na 'n alter ego kyk, is die poëtiese variant van Nijhoff (1970:27) se verwysing "toen wij leefden en geleefd werden tegelijkertijd" en 'n ekstreme konsekwensie van sy objektiveringsteorie. Die "ek" van die gedig vertrek in die gedig uit homself, objektiveer hom in voortye, vermenigvuldig hom in talle ander figure. ${ }^{1} \mathrm{Hy}$ is in

1 In die hele afdeling "Stokkiesdraai" (Driepas) word dieselfde verskynsel by Cloete aangetref. 
strofe 5 van "De wandelaar" inderdaad deur middel van 'n ruimte geskei van die wêreld en daardeur is sy kyk, sy perspektief op die wêreld vervormd: "die 'k kleiner zie en als van heel ver-af". As hy in strofe 6 sê "zagen mijn oogen" in plaas van "ik zag", is dit 'n hernude bevestiging van die objektiewe waarneming wat die hoek is van waaruit die spreker sy teks konstrueer of manipuleer én wat hy as vereiste vir die digterskap stel.

Die ruimte is "'n belangrike konstituent van die gestalte; 'n gestalte kommunikeer alleen in en deur sy ruimte" (Cloete 1984a:63). In die Nijhoffgedigte sowel as in die Cloete-gedig is die gestaltes ruimtelik gesitueer binne die gewone reële werklikheid (die tuin, die kamer, die kantien, die vakansiehotel); dit dui op 'n geosentriese gerigtheid. Die ontstaansruimte van die gedig, die plek van digterlike omsetting is dus die gewone realiteit en die uitsig deur die venster is terselfdertyd ook 'n blik op die gewoon aardse, op "'t eenvoudig leven Gods" ("Holland"). In "loopskrif in 'n vakansiehotel" bied die venster wel ook 'n sig op 'n metafisiese ruimte (die kosmos, die sterre), maar sy visie beweeg terug vanuit die metafisiese na die hier-en-nou. Die implikasie is dat hy wel tussen twee wêrelde leef, naamlik 'n aardse en 'n hemelse, maar die grootste deel waaraan hy verbonde is, is die aardse. Tog is die teenoorgestelde dikwels ook waar: die horison, die metafisiese, selfs die goddelike word dikwels gewaar, maar dan via die gewone werklikheid of vanuit 'n gewoon aardse perspektief. Die toeskouer deur die venster sien selfs soms dinge wat onbegrypbaar is en dieselfde dimensies verkry as die onaardse, soos in "het veer" van Nijhoff waar daar ook sprake is van "lamplicht door een raam" en 'n "blik naar 't venster" om :

te zien naar dingen die zij hoorde en zag maar niet bevatten kon, een trek van pijn om de vermoeide mond en van bevreemding.

\subsection{Die venster / raam as toegang vir toewaaisels van buite}

Die beeld van die digter wat voor die venster sit en skryf, is dikwels 'n demonstrasie van die teorie dat die digter "toewaaisels van buiten" kry. Hierdie magiese krag van buite wat Nijhoff (1970:10) ook "toevoegingen, die je van God bereiken" of "cadeau" van God noem, bereik die digter deur die oop venster of raam.

In aansluiting by die "cadeau"-denke, huldig Nijhoff die opvatting dat die mees intense gevoelens by die digter ontstaan in oorgangsmomente en nie in durende gevoelstoestande nie. Nijhoff noem dit "stiltes" of "oponthoude" (dit wil sê momente waar jy die sensasie so 'n bietjie vashou). Agter hierdie teorie skuil die opvatting dat die durende versteen raak. Poësie hou rekening met 
uitademing en inademing - lewe hang daarvan af. Tussen in- en uitademing ontstaan 'n oorgangsmoment of "stilte". Nijhoff (1970:14) sê hierdie stiltes is gevoelige punte waar jy die uitspraak van God hoor. Die "ingewings" of Goddelike inwaaiings kom in hierdie oorgangsmomente.

In elke digter se leksikon is daar sekere woorde wat prominensie verkry vanweë die hoë gebruiksfrekwensie daarvan. Dit gebeur soms in die digter se oeuvre dat die semantiese lading van sulke woorde wyer strek as die leksikale betekenis. 'n Digter se leksikon is dus altyd gelaai met betekeniswaardes. As Nijhoff dan praat van "stilte", dui dit ook op die stiltes (lees oorgangsmomente) van sy oeuvre.

Om terug te keer tot "Sonnet 1" van "Voor dag en dauw". In die slotstrofe van die sonnet dwing bepaalde poëtikale woorde hul aan die leser op:

De vogel is het struikgewas ontsneld.

In grote stilte gaat over het veld

het langzaam licht zich als een hand ontvouwen.

Hierdie strofe kan geïnterpreteer word as 'n versinterne poëtikale uitspraak ten opsigte van die ontstaanswyse van die gedig. Volgens De Vries (1974:48) dui "voël" volgens tradisionele simboliek op dinge insake die intellek, terwyl dit terselfdertyd verwys na 'n artefak wat geskep is. Die voël in die Nijhoff-oeuvre is inderdaad beeld van die teks of aandraer of 'inval' van die teks. ${ }^{2}$ Die plotselinge aard van die inval blyk uit die snelheid waarmee die voël die struikgewas verlaat. Die laaste twee enjamberende versreëls illustreer die langsame ${ }^{3}$ groei na samehang, die kontinue proses wat besig is om hom te voltrek deur middel van die (skrywers)hand. Die slotwoord word as gevolg van die posisionering (aan die einde van die slotstrofe) en die tydsbepaling gereleveer, sodat die implikasie is dat die proses voortstu, ten spyte van die feit dat die sonnet, soos wat dit vir die leser aan bod kom, voltooi is. Van den Akker (1985:386) lewer in dié opsig insiggewende kommentaar wat waarskynlik ook op dié bepaalde geval van toepassing is. Hy haal naamlik Valéry se uitspraak ten opsigte van die 'voltooidheid' van 'n sonnet aan: "Je les traduis par sonnet abondonné", en kommentarieer:

2 In "De schrijver" is daar byvoorbeeld spesifiek sprake van "vogels met nieuwe tekst". Cloete gebruik dieselfde beeld om die invalle van buite te illustreer in die gedig "voëls met nuwe teks": "vrou mier voël / hulle dra dag en nag teks aan".

3 Vergelyk ook Nijhoff (1970:320), se verseksterne uitspraak: “... is de samehang langzaam tot mij doorgedrongen" (my kursivering). 
In zijn visie is een gedicht nooit af - zou dat wel zo zijn, dan zou de dichter het volmaakte vers hebben geschreven - maar het wordt op een zeker moment opgegeven, de maker trekt er zijn handen van af. De Nederlandse dichter M. Nijhoff zou het in dezen met zijn Franse collega geheel eens zijn geweest.

In "loopskrif in 'n vakansiehotel" demonstreer Cloete Nijhoff se teorie dat die digter toewaaisels van buite kry én dat die mees intense gevoelens by die digter in oorgangsmomente ontstaan en nié in durende gevoelstoestande nie. In dié gedig geskied hierdie oorgangsmomente in kosmiese én aardse "ontploffings": die verskietende ster en die orgasme op die terras. Hierdie 'oponthoude' bereik die digter deur die venster en werp sy digterlike beheer omver, sodat die gedig uiteindelik sy eie koers inslaan. Die gedig ontstaan dus nié uit 'n vooropgestelde stemming of vanweë intellektuele denke nie - die gedig "valt je in". In strofe 1 en 3 is daar 'n konstellasie van opposisies wat die aard van die invalle semanties releveer:

$\begin{array}{lll}\text { beheers (strofe 1) } & \text { x } & \text { onbeheerbaar (strofe 2) } \\ \text { Binne ("in my vertrek") } & \text { x } & \text { buite ("op die terras") } \\ \text { lig ("by die lig") } & \text { x } & \text { donker ("in die aand") } \\ \text { gedempte klank ("die ritsel en kras") } & \text { x } & \begin{array}{l}\text { uitspattige, luidrugtige } \\ \text { klanke ("gier en gil") }\end{array}\end{array}$

Nijhoff se opvatting dat daar wel twee moontlikhede van inspirasie vir die digter is, naamlik die realiteit en die metafisiese, word gedemonstreer deur die feit dat dit hier gaan om 'n 'aardse' sowel as 'n kosmiese inval.

Die aard van die "ontploffmgs" wat die oponthoud veroorsaak en die beheersde skrywe omverwerp, kan waarskynlik ook om 'n tweede rede verklaar word. Ster word metafoor vir die helderheid van insig en kreatiewe energie en dít resoneer weer eens twee verseksterne uitsprake van Nijhoff (1970:12 en 16; my kursivering):

Dat was het dus, wat de taal teweegbracht: een verheldering van bewustheid binnenwaarts, en tevens van het doel buitenwaarts. Twee werelden over en weer gelijktijdig ontsloten: de inwendige en de uitwendige, en dit alles in het moment van een ademstoot.

De mens heeft een technische structuur over de wereld aangelegd, en deze structuur werkt even perfect als de jaargetijden, als dag en nacht, als geboorte en dood in de natuur. De tram is een ster, de politie-agent is een 
ster, al zijn het sterren langs hun banen voortbewogen door een door mensen, massa's van mensen, geslachten van mensen, geschapen drijkracht.

Die seksuele energie van die "orgasme onbeheerbaar op die terras" word metafoor vir die kreatiewe energie en dien terselfdertyd as teenvoeter vir die beheersde skrywe in die vertrek. Nijhoff was die eerste digter na die geslag van Tagtig in wie se werk daar so ' $n$ bewustheid is van die geweldige kragte wat werksaam is in die menslike gees en wat dan in die teks gestalte kry. By Cloete is daar dieselfde bewussyn: die ontploffings buite is terselfdertyd beeld van hierdie magiese kragte in die menslike gees.

Soos Nijhoff is Cloete skerp sintuiglik ingestel - in al die gesiteerde Nijhofftekste, sowel as in die Cloete-teks, bereik die invalle van buite die digter visueel en ouditief. Die skrywer 'sien' deur die venster en die pen staan "luisterend" orent. Dat die ontstaan van die gedig 'n kontinue proses is, is ook af te lei uit die deelwoord "luisterend". Die semantiese veld wat deur "luisterend" geaktiveer word, is 'n oomblik van stilte, of stilstand - 'n toestand wat korrespondeer met Nijhoff se "stiltes" van die oorgangsmomente.

\section{3 "Het interne eigen-leven van het gedicht"}

Die selfaangedrewenheid van die gedig word uitvoerig deur Nijhoff (1982b) uiteengesit in die geskrif "De pen op papier". Die opvatting dat daar 'n magiese hand is wat die skrywer se hand vat as hy skryf en eintlik sy handskrif skryf, word versintern in Cloete se gedig uitgespel, want "die hand gaan aan en aan /waar dit daar aan die loop gaan". Die semantiese strekking word terselfdertyd klankmatig gemanifesteer in die herhaling van die [a:]-klank in die laaste strofe:

en gaan aan en aan

waar dit daar aan die loop gaan

Die kreatiewe energie van taal en die eiesinnigheid van die teks is ' $n$ baie belangrike faset van Cloete, maar ook van Nijhoff se versinterne (sowel as verseksterne ) poëtika. Die dwang wat die maak van poësie op die digter plaas, spreek Cloete versintern in verskillende gedigte in sy oeuvre uit. Van den Akker (1985:140) maak selfs die stelling dat die hoeksteen van Nijhoff se poëtika "de autonomie van het gedicht" is.

Komrij (1984:22) se konsepsie in verband met taal word vervolgens aangehaal, aangesien dit vanuit die oogpunt van die digter die wyse waarmee taal met die digter omgaan, so tekenend weergee: 
De taal gaat ook met ons om. Wie een vol wit papier voor zich neemt om daaraan toe te vertrouwen wat hij aanziet voor eigen gedachten, voor invallen uit vrije wil, kan misschien enige tijd in die waan blijven verkeren, maar er komt een moment waarop het metrum, de adem en de slagorde van de woorden basta zeggen, en ingrijpen. Ze doen iets terug, ze dringen zich aan ons op. Dat is een van de wonderlijkste aspecten van het schrijven: het altijd weer terugkerende moment [...] waarop de pen geen woorden loslaat, maar de woorden de pen besturen. Geen kalligrafie van het hogere, van de Onzienlike is dat, maar een zichtbare, vitale eigenschap van de taal.

Nijhoff se uitspraak dat die skrywer moet verdwyn in sy werk, word by implikasie ook deur Cloete gekonstateer. In strofe 1 en in strofe 4 is daar sprake van "my" pen. As die gedig sy eie loop neem, word die besitlike voomaamwoord "my" vervang met die lidwoord "die" - in plaas van "my hand" dus "die hand". Hier is 'n eksplisiete manifestasie van die feit dat die digter gedurende die kreatiewe proses 'verdwyn'; die kreatiewe resultaat van die skrywer se uitdrukkingsorgane is nie meer déél van hom nie.

Volgens Nijhoff se drieledigheidsteorie is daar in die gedig 'n eerste inhoud/konsepsie, wat na vorm soek, maar die vorm sélf skep 'n tweede inhoud/konsepsie. Hierdie drieledigheidsteorie is by implikasie ook in "loopskrif in 'n vakansiehotel" ingebed. By Nijhoff vind dié teorie dikwels neerslag in die struktuur van die gedig - vergelyk byvoorbeeld "Het derde land" (Nijhoff 1970:104) - dieselfde geld vir die Cloete-gedig. Hierdie gedig bestaan uit ses strofes van afwisselende lengte: vier versreëls, een, vier, een, vier, twee. Ook in die klankstruktuur is daar 'n funksionele organisatoriese faktor ten opsigte van die rymklanke: abab c abab c dede ff. Daar is dus duidelik ekstra patroonvorming en afwyking in die slotstrofe. Die genoemde afwyking in die strofeverdeling en rymskema, sowel as die opeenstapeling van die rymklank in strofe 6, releveer dié slotstrofe en manifesteer terselfdertyd die seniantiese strekking daarvan. Die eiesinnigheid van taal, en ook die eiesinnigheid van die gedig, word dus formeel én konseptueel, sintakties én semanties gekommunikeer. In strofe 1 en 2 is die konsepsie: "ek sit en skryf ... beheers" en "ek sien". In strofe 4 is die digterlike beheer omvergewerp deur indrukke van buite en die gevolg is: "my pen staan luisterend in my hand" daar word dus na vorm (woorde) gesoek ("een gedicht bestaat uit woorde, niet uit gedachten"). In strofe 5 kry die hand wat koud geword "weer loop", soek 'n nuwe behoud (wat klankmatig verband lê met inhoud) en "gaan aan en aan" in strofe 6. Daar is dus nou 'n tweede konsepsie: geen beheersde skryfwyse meer 
nie, maar 'n eie koers, 'n gedig met 'n "interne eigen-leven". 4

\section{Samevatting}

T.T. Cloete se gedig wat hier bespreek is, toon duidelike knooppunte met geskrifte van sy gekanoniseerde Nederlandse voorganger Martinus Nijhoff. Enkele interaktiewe poëtikale opvattings van Cloete en Nijhoff is in die loop van die artikel uitgewys. Die kern van die gemeenskaplike opvattings setel in die konsep van die eiesinnigheid van taal, wat op sinkroniese niveau aansluit by die sogenaamde outonomistiese poëtika van die Utrechtse model. (Vergelyk Sötemann, 1985.) Die aanname kan dus gemaak word dat Cloete wel ook binne die breë (internasionale) poëtikale tradisie van taaleiesinnigheid gelees kan word. Deur sy besondere bemoeienis met die Nederlandse literêre tradisie aktualiseer hy 'n ruimer tradisie binne 'n Afrikaanse konteks en verruim hy terselfdertyd die Afrikaanse literêre tradisie.

\section{Bibliografie}

Bakker, M. 1987. "Ik zag de nieuwe brug": een systematisch onderzoek naar het nieuwe van Nijhoffs Nieuwe Gedichten. Amsterdam : De Arbeiderspers.

Cloete, T.T. 1970. J.H. Leopold oor die dromende denke. In: Cloete, T.T. Kaneel. Kaapstad : Nasionale Boekhandel. pp. 167-196.

Cloete, T.T. 1984a. Wat is literatuur? Potchefstroom : PU vir CHO. (Wetenskaplike bydraes van die PU vir CHO. Reeks A nr. 50.)

Cloete, T.T. 1984b. Die dromende denke van die digter. In: SAVALkongresreferate IV. Pretoria : SAVAL. pp. 1-20.

Cloete, T.T. 1985. Ongepubliseerde honneurslesings aangebied te PU vir CHO.

Cloete, T.T. 1986. Idiolek. Kaapstad : Tafelberg.

Cloete, T.T. 1989. Driepas. Kaapstad : Tafelberg.

De Vries, A. 1976. Dictionary of Symbols and Imagery. Amsterdam : NorthHolland.

Komrij, G. 1984. Alles onecht: keuze uit de gedichten. Amsterdam : De Arbeiderspers.

Marsman, H. 1925. Traditie en vernieuwing. In: Verzameld werk in drie deelen. Amsterdam : Querido's. pp. 236-238.

4 Marsman (1925:243) maak die belangrike uitspraak: "lk deel Nijhoff 's inzichten over het interne eigen-leven van het het gedicht volkomen." 
Nel, A. 1992. Die allotropie van "gevormde literatuur" in die poësie van T.T. Cloete -'n ondersoek na die idiolektiese "omzetting" van Nederlandse tekste. Pretoria : Universiteit van Pretoria. (D.Litt-proefskrif.)

Nijhoff, M. 1970. Lees maar, er staat niet wat er staat. Den Haag : Bert Bakker.

Nijhoff, M. 1982a. Verzameld werk 1. Amsterdam : Bert Bakker.

Nijhoff, M. 1982b. Verzameld werk 2. Amsterdam : Bert Bakker.

Sötemann, A.L. 1985. Over poetica en poëzie: een bundel beschouwingen samengesteld en ingeleid door W.J. van den Akker en G.J. Dorleijn. Groningen : Wolters-Noordhof.

Van den Akker, W. 1985. Een dichter schreit niet: de poetica van M. Nijhoff: aspecten van $M$. Nijhoffs versexterne poetica. Utrecht : Veen. 
